\title{
Exogenous Proline and Glycine Betaine in Plants under Stress Tolerance
}

\author{
Kanu Murmu ${ }^{1 *}$, Sidhu Murmu ${ }^{2}$, Champak Kumar Kundu ${ }^{1}$ and Purnendu Sekhar Bera ${ }^{1}$ \\ ${ }^{1}$ Department of Agronomy, F/Ag, Bidhan Chandra Krishi Viswavidyalaya, P.O- Krishi \\ Viswavidyalaya, Mohanpur - 741252, Nadia (WB), India \\ ${ }^{2}$ Department of Agricultural Chemistry and Soil Science, F/Ag, Bidhan Chandra Krishi \\ Viswavidyalaya, P.O- Krishi Viswavidyalaya, Mohanpur - 741252, Nadia (WB), India \\ *Corresponding author
}

\begin{tabular}{|l|}
\hline Ke y w or d s \\
$\begin{array}{l}\text { Proline, Glycine } \\
\text { betaine, Stress } \\
\text { tolerance. }\end{array}$ \\
\hline Article Info \\
\hline $\begin{array}{l}\text { Accepted: } \\
\text { 14 July } 2017 \\
\text { Available Online: } \\
\text { 10 September } 2017\end{array}$ \\
\hline
\end{tabular}

\section{Introduction}

The productivity and spatial distribution of plants, particularly many agronomical and horticultural crop plants of commercial importance, are severely restricted by a variety of environmental factors. Several environmental factors adversely affect plant growth and development and final yield performance of a crop. Drought, salinity, nutrient imbalances (including mineral toxicities and deficiencies) and extremes of temperature are among the major environmental constraints to crop productivity worldwide. When plants experience the unfavorable environmental conditions associated with high levels of salt, drought or low temperature, plant cells protect themselves from the stress of high concentrations of intracellular salts by accumulating a variety of small organic metabolites that are referred to collectively as compatible solutes (Bohnert et al., 1995). It is estimated that less than $10 \%$ of the world's arable lands may be free of major environmental stresses (Dudal, 1976), with drought and salinity stresses being the most widespread (Ashraf, 1994). For instance, up 
to $45 \%$ of the world agricultural lands are subject to continuous or frequent drought, wherein $38 \%$ of the world human population resides (Bot et al., 2000), and worldwide area mapped as being affected by salinity is more than $3 \times 106 \mathrm{~km} 2$, or approximately $6 \%$ of the total land area (Flowers et al., 1977). Also, $19.5 \%$ of the irrigated agricultural lands are considered saline (Flowers and Yeo, 1995). Furthermore, each year there is a deterioration of 2 million ha (about 1\%) of world agricultural lands to salinity, leading to reduced or no crop productivity (ChoukrAllah, 1995). Low precipitation, high surface evaporation, weathering of native rocks, irrigation with saline water, and poor cultural practices are among the major contributors to the increasing salinity. Secondary salinization, in particular, exacerbates the problem where once productive agricultural lands are becoming unfit to cultivation due to poor quality irrigation water.

Changes in ambient temperature occur more rapidly than changes in stress factors such as drought, salinity and nutrient imbalances. Furthermore, temperature extremes aggravate the adverse effects of other stresses, including drought and salinity, on crop production and quality. For instance, heat stress adversely affects grain quality and final crop yield in $40 \%$ of the irrigated wheat growing area of the world (Fischer and Byerlee, 1991).

The impact of global warming differs regionally, and it is envisaged that developing countries will be affected to a greater extent, thereby resulting in increased food insecurity therein (Rosenzweig and Parry, 1994). Cold stress, although seasonal, has some similarities to drought stress, because as water freezes it creates concentrated solutions of solutes, thereby subjecting plants to a shortage of liquid water. Compatible solutes are defined as small molecules that are very soluble in water and are also uniformly neutral with respect to the perturbation of cellular functions, even when present at high concentrations (Yancey et al., 1982). The properties of compatible solutes allow the maintenance of turgor pressure during water stress, which is an intrinsic feature of major forms of abiotic stress such as salt and cold stress. In addition, some compatible solutes can serve as efficient protective agents by stabilizing the structures and functions of certain macromolecules (Santoro et al., 1992; Papageorgiou and Murata 1995). Thus, it is widely accepted that the accumulation of these compounds in plants contributes in a fundamentally important manner to the acclimatization of cells to environmental stress, even though the vast preponderance of the evidence that supports this view remains circumstantial. Representative compatible solutes include certain polyols, sugars, amino acids, betaines and related compounds (Bohnert and Jensen 1996; Hayashi and Murata 1998).

\section{Proline}

\section{Natural production and accumulation}

Amino acid proline is known to occur widely in higher plants and normally accumulates in large quantities in response to environmental stresses (Kavi Kishore et al., 2005). In addition to its role as an osmolyte for osmotic adjustment, proline contributes to stabilizing sub-cellular structures (e.g. membranes and proteins), scavenging free radicals, and buffering cellular redox potential under stress conditions. It may also function as a protein compatible hydrotrope alleviating cytoplasmic acidosis, and maintaining appropriate $\mathrm{NADP}+\mathrm{NADPH}$ ratios compatible with metabolism (Hare and Cress, 1997). Also, rapid breakdown of proline upon relief of stress may provide sufficient reducing agents that support mitochondrial oxidative phosphorylation and generation of 
ATP for recovery from stress and repairing of stress-induced damages (Hare and Cress, 1997; Hare et al., 1998). Furthermore, proline is known to induce expression of salt stress responsive genes, which possess proline responsive elements (e.g. PRE, ACTCAT) in their promoters (Satoh et al., 2002; Chinnusamy et al., 2005).

In response to drought or salinity stress in plants, proline accumulation normally occurs in the cytosol where it contributes substantially to the cytoplasmic osmotic adjustment (Ketchum et al., 1991). For example, in cells of Distichlisspicata treated with $200 \mathrm{mM} \mathrm{NaCl}$, the cytosolic proline concentration was estimated to be more than 230mM (Ketchum et al., 1991).

In apical region of maize roots growing at a water potential of $-1.6 \mathrm{MPa}$, proline concentration reached approximately $120 \mathrm{mM}$ and accounted for upto $50 \%$ of the osmotic adjustment (Voetberg and Sharp, 1991).Furthermore, it was determined that, in response to water deficit, increased concentration of proline in maize root apical meristem was paralleled with increased concentration of abscisic acid (Ober and Sharp, 1994; Sharp et al., 1994).

In plants, the precursor for proline biosynthesis is 1-glutamic acid. Two enzymes, pyrroline-5-carboxylate synthetase (P5CS) and pyrroline-5-carboxylate reductase (P5CR), play major roles in proline biosynthetic pathway (Delauney and Verma, 1993) (Fig. 1). Transgenic tobacco plants over-expressing P5CS have shown increased concentration of proline and resistance to both drought and salinity stresses (Kishor et al., 1995). However, whether proline accumulation in these transgenic plants resulted in increased stress tolerance through osmotic adjustment or other mechanisms is unknown (Sharp et al., 1996).

\section{Glycine betaine}

\section{Natural production and accumulation}

Among the many quaternary ammonium compounds known in plants, glycine betaine (GB) occurs most abundantly in response to dehydration stress (Venkatesan and Chellappan, 1998; Yang et al., 2003). GB is abundant mainly in chloroplast where it plays a vital role in adjustment and protection of thylakoid membrane, thereby maintaining photosynthetic efficiency (Robinson and Jones, 1986; Genard et al., 1991). In higher plants, GB is synthesized in chloroplast from serine via ethanolamine, choline, and betaine aldehyde (Hanson and Scott, 1980). Choline is converted to betaine aldehyde, by choline mono oxygenase (CMO), which is then converted to GB by betaine aldehyde dehydrogenase (BADH) (Fig. 2). Although other pathways such as direct $\mathrm{N}$-methylation of glycine is also known, the pathway from choline to glycine betaine has been identified in all GB-accumulating plant species (Weretilnyk et al., 1989). GB is known to accumulate in response to stress in many crop plants, including sugar beet (Beta vulgaris), spinach (Spinacia oleracea), barley (Hordeum vulgare), wheat (Triticum aestivum), and sorghum (Sorghum bicolor) (Weimberg et al., 1984; Yang et al., 2003).

In these species, tolerant genotypes normally accumulate more GB than sensitive genotypes in response to stress. This relationship, however, is not universal. For example, no significant correlation was observed between accumulation of GB and salt tolerance in various species of Triticum, Agropyron, and Elymus (Wyn Jones et al., 1984), and even higher concentrations of choline and betaine were observed in salt-sensitive than salttolerant lines of Egyptian clover (Trifolium alexandrinum) under salt stress (Varshney et al.,1988). Also, cell lines of lemon (Citrus 
limon) selected under salt stress did not exhibit a significant increase in GB when compared with non-selected (control) cells (Piqueras et al., 1996). However, it is likely that the relationship between GB accumulation and stress tolerance is speciesor even genotype specific.

\section{Effect of Glycine Betaine (GB)}

Glycine betaine (N, N, N-trimethylglycine) is an amphoteric compound that is electrically neutral over a wide range of physiological $\mathrm{pH}$ values. It is extremely soluble in water but includes a non-polar hydrocarbon moiety that consists of three methyl groups. The molecular features of GB allow it to interact with both hydrophilic and hydrophobic domains of macromolecules, such as enzymes and protein complexes. Studies in vitro have indicated that GB is not merely a nontoxic, cellular osmolyte that raises intracellular osmolarity when a cell is exposed to stressinduced hyperosmotic conditions: it has been well documented that, in vitro, GB stabilizes the structures and activities of enzymes and protein complexes and maintains the integrity of membranes against the damaging effects of excessive salt, cold, heat and freezing (Gorham 1995). Although much attention has been paid to the mechanism(s) of action of $\mathrm{GB}$, full details have not yet been firmly established. Indeed, two mutually exclusive hypotheses have been proposed for the mechanism whereby GB stabilizes macromolecular structures. From the results of biophysical analysis, Arakawa \& Timasheff (1983) proposed that GB is preferentially excluded from contact with a protein so that a hydration shell (layers of bound water) can be maintained around the surface of the protein. This 'preferential hydration activity' stabilizes the native structure of the protein. In contrast, Schobert (1977) attributed the stabilizing effect of GB to its direct interaction with a protein.
According to Schobert, the hydrophobic portion of $\mathrm{GB}$ binds to the hydrophobic domains of the protein, from which bound water is readily released when there is a water deficit. Acting in this way, GB allows the hydrophobic domains of the protein to become more accessible to water, preventing the protein from the denaturation that would otherwise be caused by dehydration (Table 2).

\section{Salt tolerance}

It has been demonstrated, through studies of both plant physiology and genetics, that the level of accumulated GB is correlated with the degree of salt tolerance (Rhodes et al., 1989; Saneoka et al., 1995). Moreover, an exogenous supply of GB also increases the salt tolerance of some plants that are otherwise unable to accumulate GB (Harinasut et al., 1996; Hayashi et al.,1998).To obtain direct proof that the accumulation of GB in vivo enhances the ability of plants to tolerate high concentrations of salt, studies were made of the physiological consequences of the transgenic engineering of GB synthesis via overexpression of two choline-oxidizing enzymes, namely COD and CDH (Hayashi et al., 1997, 1998; Holmström et al., 2000). Transgenic Arabidopsis plants that produced COD in their chloroplasts not only acquired resistance to high concentrations of $\mathrm{NaCl}$ during germination but also were able to tolerate high levels of salt during the subsequent growth of seedlings and mature plants (Hayashi et al., 1997, 1998). Transformation of tobacco with a gene for $\mathrm{CDH}$ also enhanced plant growth under salt stress, although the level of GB was much lower than that in 'COD-engineered' Arabidopsis (Holmström et al., 2000). In addition, Brassica juncea and Japanese persimmon (Diospyros kaki) have been successfully transformed to tolerate salt stress through the introduction and over expression 
of a gene for COD (Gao et al., 2000; Prasad et al., 2000a).

\section{Cold tolerance}

It has been proposed that GB that is supplied exogenously can protect higher plants against stress due to low temperatures (Kishitani et al., 1994; Chen et al., 2000). Genetic engineering of Arabidopsis that resulted in the expression of COD significantly increased tolerance to low temperatures at various stages of development.

The seeds of transgenic plants were more tolerant to low temperatures during imbibition and germination with higher frequencies and accelerated rates of germination, respectively, than controls (Alia et al., 1998a).

The production of biomass by both young and mature plants of the transgenic strain of Arabidopsis was also enhanced at low temperatures, as compared with controls (Hayashi et al., 1997; Alia et al., 1998a).

\section{Heat tolerance}

High temperatures also limit the growth and productivity of plants. Early experiments in vitro indicated that GB protects some enzymes and protein complexes from heat induced destabilization (see Gorham 1995 and references therein). Therefore, it has been postulated that GB increases resistance to high-temperature stress. More recent experiments showed that transformed Arabidopsis that accumulated GB exhibited enhanced tolerance to high temperatures during the imbibitions and germination of seeds, as well as during the growth of young seedlings (Alia et al., 1998b). It also seems likely that GB might alleviate the effects of heat shock because the extent of the induction of heat-shock proteins was significantly reduced in these transgenic plants.

\section{Freezing tolerance}

It has been reported that GB has a cryo protective effect in vitro on enzymes and membranes (for review, see Gorham 1995) and that an exogenous supply of GB improves the ability of plants to tolerate freezing stress (Allard et al., 1998; Sakamoto et al., 2000). In support of these observations, (Sakamoto et al., 2000) shows that the transformation of Arabidopsis with the $\operatorname{cod} A$ gene for COD enhanced freezing tolerance significantly when tolerance was evaluated in terms of viability and the retention of intracellular ions after freezing treatments. Cold-regulated proteins, which have been implicated in the development of freezing tolerance (JagloOttosen et al., 1998), did not seem to be responsible for the enhanced freezing tolerance of these transgenic plants, because levels of these proteins were unaffected by the transformation.

\section{Proline accumulation and stress tolerance}

For a long time, proline was considered as an inert compatible osmolyte that protects subcellular structures and macromolecules under osmotic stress (Csonka and Hanson 1991) However, proline accumulation can influence stress tolerance in multiple ways (Figure 3). Proline has been shown to function as a molecular chaperone able to protect protein integrity and enhance the activities of different enzymes. Examples of such roles include the prevention of protein aggregation and stabilization of M4 lactate dehydrogenase during extreme temperatures, protection of nitrate reductase during heavy metal and osmotic stress (Sharma and Dubey, 2005) and stabilization of ribonucleases and proteases upon arsenate exposure. Several studies have attributed an antioxidant feature to proline, suggesting ROS scavenging activity and proline acting as a singlet oxygen quencher (Smirnoff and Cumbes, 1989) 
Proline treatment can diminish ROS levels in fungi and yeast, thus preventing programmed cell death (Chen and Dickman, 2005) can protect human cells against carcinogenic oxidative stress (Krishnan et al.,2008), and can reduce lipid peroxidation in alga cells exposed to heavy metals (Mehta, S.K. and Gaur, J.P. 1999) Proline pretreatment also alleviated $\mathrm{Hg}_{2}{ }^{+}$toxicity in rice (Oryza sativa) through scavenging ROS, such as $\mathrm{H} 2 \mathrm{O} 2$ (Wang et al., 2009). The damaging effects of singlet oxygen and hydroxyl radicals on Photosystem II (PSII) can be reduced by proline in isolated thylakoid membranes (PSII) (Alia and Mohanty, 1997). Free radical levels were reduced in transgenic algae and tobacco plants engineered for hyperaccumulation of proline by P5CS over expression and acceleration of the proline biosynthetic pathway. By contrast, compromised proline accumulation in p5cs1 insertion mutants led to accumulation of ROS and enhanced oxidative damage (Szekely et al., 2008). A similar effect was observed in yeast, where low proline levels in PUT1 (proline dehydrogenase)-over expressing lines led to enhanced ROS, whereas higher proline content in put1 mutants correlated with increased protection from oxidative damage (Chen et al., 2006). As an alternative to direct ROS scavenging feature, proline can protect and stabilize ROS scavenging enzymes and activate alternative detoxification pathways. In salt-stressed tobacco cells, proline increased the activities of methylglyoxal detoxification enzymes, enhanced peroxidase, glutathion-S-transferase, superoxide dismutase and catalase activities, and increased the glutathione redox state (Hoque et al., 2008). In the desert plant Pancratium maritimum, catalase and peroxidase were found to be stabilized by proline during salt stress. The salthypersensitivep5cs1 Arabidopsis mutant shows reduced activities of key antioxidant enzymes of the glutathione ascorbate cycle, leading to hyper accumulation of $\mathrm{H} 202$, enhanced lipid peroxidation and chlorophyll damage (Szekely et al., 2008).As well as having protective or scavenging features, it is feasible that proline metabolism can stabilize cellular homeostasis during stress conditions in way that is still poorly understood. Accumulation of P5CS1 and P5CR in chloroplasts during salt stress suggests that, under adverse conditions, glutamate-derived proline biosynthesis increases in plastids, where photosynthesis occurs. During stress conditions, the rate of the Calvin cycle is diminished, which prevents oxidation of NADPH and restoration of NADP+. When combined with high light, electron flow in the electron transport chain is suppressed by the insufficient electron acceptor NADP+ pool, leading to singlet oxygen production in the PSI reaction center and accumulation of ROS Chaves et al., 2009). Proline biosynthesis is a reductive pathway, and requires NADPH for the reduction of glutamate to P5C and P5C to proline, and generates NADP+ that can be used further as electron acceptor. The phosphorylation of glutamate consumes ATP and produces ADP, which is a substrate for ATP biosynthesis during photosynthesis. An enhanced rate of proline biosynthesis in chloroplasts during stress can maintain the low NADPH: NADP+ ratio, contribute to sustaining the electron flow between photosynthetic excitation centers, stabilize the redox balance, and reduce photo inhibition and damage of the photosynthetic apparatus (Hare and Cress, 1997). In transgenic soybean plants, the inhibition of proline biosynthesis and NADPH-NADP+ conversion by antisense P5CR led to drought hypersensitivity, whereas over expression of P5CR resulted in moderate drought tolerance, confirming that proline biosynthesis is important for maintaining NADP+ pools during stress (De Ronde et al., 2004) (Table $1)$. 
Table.1 Summary of the effects of exogenous application of proline on different plant species

\begin{tabular}{|c|c|c|c|}
\hline Plant species & Stress & Effect of exogenous proline & Reference \\
\hline Distichlisspicata & Salt & $\begin{array}{l}\text { Proline accumulation was high in cells adapted to a } \\
\text { concentration of salt }\end{array}$ & Heyser et al, (1989) \\
\hline Glycine $\max$ & Salt & $\begin{array}{l}\text { Proline application increased production of superoxide } \\
\text { dismutase and peroxidase in stressed plants }\end{array}$ & $\begin{array}{l}\text { Yan et al, (2000) and Hua and Guo } \\
(2002)\end{array}$ \\
\hline $\begin{array}{l}\text { Allenrolfea } \\
\text { occidentalis }\end{array}$ & Salt and drought & $\begin{array}{l}\text { Proline neutralized the increased ethylene production in } \\
\text { stressed plants }\end{array}$ & Chrominski et al., (1989) \\
\hline Hordeum vulgare & Salt & $\begin{array}{l}\text { Proline caused a decrease in shoot } \mathrm{Na}^{+} \text {and } \mathrm{Cl}^{-} \\
\text {accumulation in embryo culture cells }\end{array}$ & Lone et al., (1987) \\
\hline Allium сера & Salt & $\begin{array}{l}\text { Proline resulted in mitigating the effect of } \mathrm{NaCl} \text { on cell } \\
\text { membrane disruption }\end{array}$ & Mansour (1998) \\
\hline Oryza sativa & Salt & $\begin{array}{l}\text { Proline did not alter leaf } \mathrm{Na}^{+} \text {and } \mathrm{Cl}^{-} \text {contents in } \\
\text { salt-stressed plants }\end{array}$ & Krishnamurthy and Bhagwat (1993) \\
\hline $\begin{array}{l}\text { Nicotiana tabacum } \\
\text { Arabidopsis }\end{array}$ & Salt & Proline promoted the growth of suspension cells under salt & Krishnamurthy and Bhagwat (1993) \\
\hline thaliana & No stress & $\begin{array}{l}\text { Proline caused damages to chloroplast and mitochondria } \\
\text { ultra-structures }\end{array}$ & Hare et al., (2002) \\
\hline
\end{tabular}

Table.2 Summary of the effects of exogenous application of glycine betaine on different plant species

\begin{tabular}{|c|c|c|}
\hline Plant Species & Stress & Effect of exogenous GB \\
\hline Nicotiana tabacum & Drought & $\begin{array}{l}\text { GB induced improvement in growth and yield o } \\
\text { water-stressed plants }\end{array}$ \\
\hline Phaseolus vulgaris & Drought & $\begin{array}{l}\text { GB-treated plants showed a slower decrease in } \\
\text { leaf } \\
\text { water potential }\end{array}$ \\
\hline Glycine max & Drought & GB improved growth \\
\hline Triticum aestivum & Drought & $\begin{array}{l}\text { (i) GB improved growth } \\
\text { (ii) GB did not improve growth }\end{array}$ \\
\hline Brassica napus & Drought & GB did not improve growth \\
\hline Zea mays & Drought & GB improved growth of stressed plants \\
\hline $\begin{array}{l}\text { Lycopersicon } \\
\text { esculentum }\end{array}$ & $\begin{array}{l}\text { Salt and high } \\
\text { temperature }\end{array}$ & GB improved growth of stressed plants \\
\hline Oryza sativa & Salt & $\begin{array}{l}\text { (i) GB improved growth of salt-stressed plants } \\
\text { (ii) GB improved shoot growth but not root } \\
\text { growth } \\
\text { (iii) GB-treated salt-stressed plants had lower } \\
\mathrm{Na}^{+} \\
\text {and higher } \mathrm{K}^{+} \text {in the shoot } \\
\text { GB improved freezing tolerance (reduced }\end{array}$ \\
\hline Arabidopsis thaliana & Freezing tempera & $\begin{array}{l}\text { freezing } \\
\text { temperature from }-3.1 \text { to }-4.5^{\circ} \mathrm{C} \text { ) }\end{array}$ \\
\hline Solanumtuberosum & Low temperature & $\begin{array}{l}\text { GB improved growth of stressed plants } \\
\text { (i) GB improved growth and yield of stressed }\end{array}$ \\
\hline Gossypiumhirsutum & Drought & $\begin{array}{l}\text { plants } \\
\text { (ii) GB did not improve growth and yield of } \\
\text { stressed } \\
\text { plants }\end{array}$ \\
\hline
\end{tabular}

Reference

GB induced improvement in growth and yield of Agboma et al., (1997b)

water-stressed plants

GB-treated plants showed a slower decrease in

water potential

GB improved growth

(i) GB improved growth

(ii) GB did not improve growth

GB did not improve growth

GB improved growth of stressed plants

WeiBing and Rajashekar (1999)

Agboma et al., (1997c)

Borojevic et al., (1980)

Agboma et al., (1997a)

Makela ${ }^{\circ}$ et al., (1996)

Agboma et al., (1997a)

Makela ${ }^{\circ}$ et al. (1998a,b)

Harinasut et al., (1996) and Lutts (2000)

Lutts (2000) and Rahman et al., (2002)

Lutts (2000) and Rahman et al., (2002)

WeiBing and Rajashekar (2001)

Somersalo et al., (1996)

Naidu et al., (1998) and Gorham et al., (2000)

Meek et al., (2003) 
Fig.1 Biosynthetic pathway of proline in higher plants

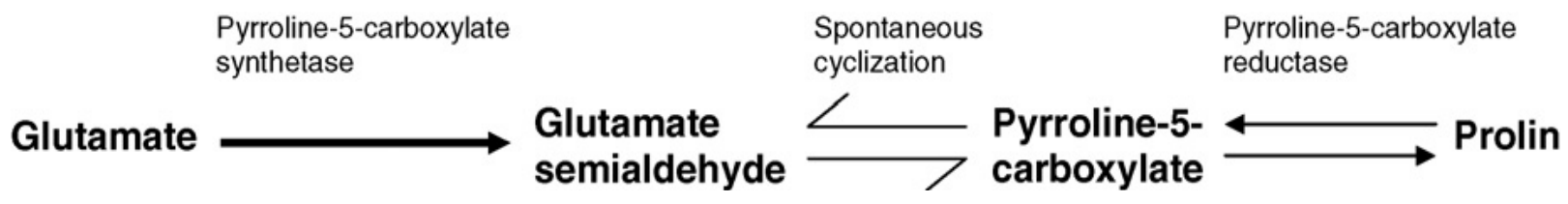

Fig.2 Biosynthetic pathway of glycine betaine in higher plants

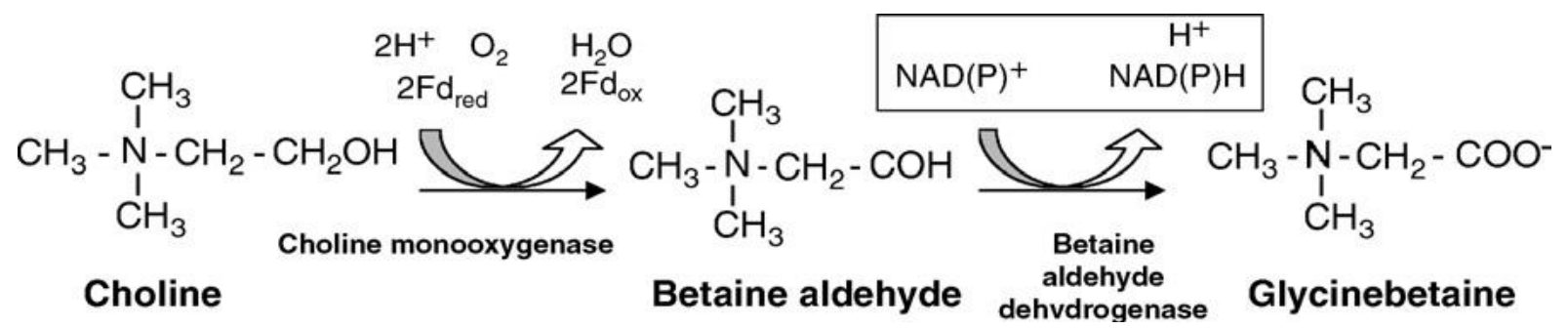

Fig.3 Multiple functions of proline in plants. Proline is used for protein synthesis, has protective functions as an osmolyte, contributes to the maintenance of the redox balance, can regulate development and is a component of metabolic signaling networks controlling mitochondrial functions, stress relief and development. Abbreviations: APX, ascorbate peroxidase; CAT, catalase; PCD, programmed cell death

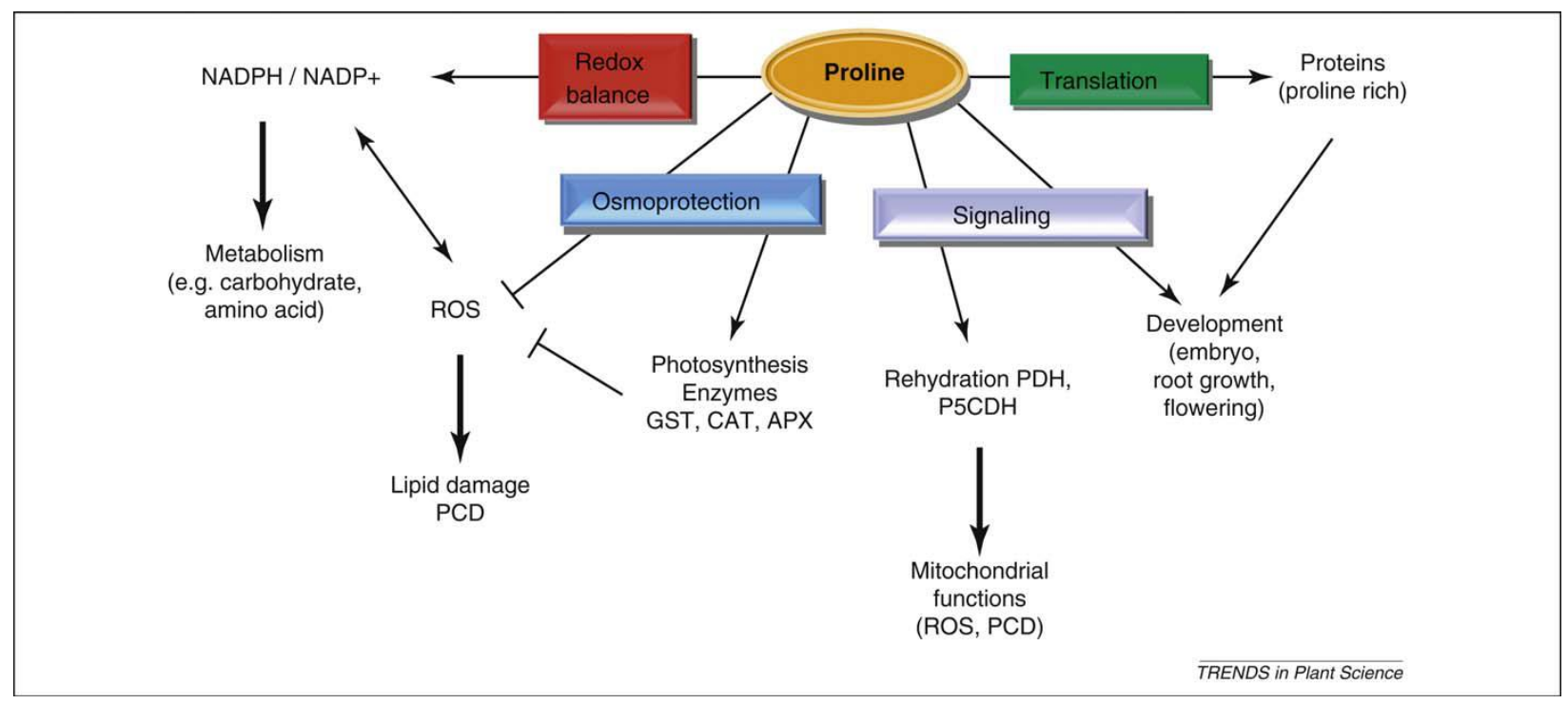

Such a connection between photosynthesis and proline metabolism is supported by lightdependent proline accumulation, which is regulated by the light-controlled reciprocal P5CS and PDH gene activation.

In mitochondria, proline has distinct protective functions. After stress, proline pools supply a reducing potential for mitochondria through the oxidation of proline by $\mathrm{PDH}$ and $\mathrm{P} 5 \mathrm{CDH}$, provide electrons for the respiratory chain and therefore contribute to energy supply for resumed growth (KaviKishor et al., 2005) Proline was shown 
to protect Complex II of the mitochondrial electron transport chain during salt stress and therefore stabilized mitochondrial respiration. The recently discovered $\mathrm{P} 5 \mathrm{C}$-proline cycle can deliver electrons to mitochondrial electron transport without producing glutamate and, under certain conditions, can generate more ROS in the mitochondria. Proline catabolism is, therefore, an important regulator of cellular ROS balance and can influence numerous additional regulatory pathways. Although species-specific differences in proline accumulation exist, it is an open question whether differences in proline accumulation have an adaptive value.

Halophyte relatives of Arabidopsis, such as Thellungiella halophile and Lepidium crassifolium, have elevated proline levels under unstressed conditions and accumulate proline to higher levels than does Arabidopsis when exposed to high salinity. In Thellungiella, high proline accumulation results from enhanced P5CS and reduced PDH expression levels (Kant et al., 2006) High proline levels can improve the salt tolerance of the halophyte plant Pancratium maritimum, by stabilizing detoxifying enzymes and protein turnover machinery and stimulating the accumulation of stress protective proteins (Khedr et al., 2003) Other halophytes, such as Camphor osmaannua or Limonium spp, do not have high proline content; instead, they accumulate carbohydrate or betain-derived osmolytes (Gagneul et al., 2007) In Silene vulgaris, constitutive proline content was higher in metal-tolerant ecotypes, whereas metalinduced proline accumulation was higher in a non-tolerant ecotype (Schat et al., 1997) The capacity for proline hyper accumulation therefore accompanies the extremophile character of certain plant species and is likely that it contributes to their stress tolerance; however, it is not an absolute requirement for adaptation to extreme environmental conditions.

\section{Future prospects}

Glycine betaine appears to play an important role in the responses of plant cells to a variety of stresses, and transgenic approaches have shed some light on the ways in which GB protects plants from stress. Current research efforts are focused on the elucidation of the mechanisms by which GB protects the cellular machinery in vivo and how, as a result, it enhances the tolerance of whole plants to environmental stress. Despite recent progress in characterization of the protective actions of $\mathrm{GB}$ in transgenic plants, there remains a critical gap, in terms of the protective effects of $\mathrm{GB}$, between phenomena in vivo and in vitro. This gap is exemplified by the difference between the effective concentrations of GB. Transgenic plants accumulate GB at levels of $50-100 \mathrm{mM}$ at most, with substantial effects on stress tolerance. However, all the possible effects of GB on stress protection that have been inferred from experiments in vitro involve much higher concentrations of GB, such as 1 M. Further studies of transgenic plants are necessary, particularly at the cellular level, to address this issue and resolve the discrepancy. Finally, the application of new technologies such as DNA arrays and proteome analysis should help to reveal additional possible functions of $\mathrm{GB}$ in vivo, for instance the maintenance of transcription and translation under stress conditions (Gibson et al., 1984; Rajendrakumar et al., 1997). The eventual practical goal of all these studies is the improvement of vital food crops that grow under high-stress conditions worldwide.

Many plant species naturally accumulate GB and proline as major organic osmolytes when subjected to different abiotic stresses. These compounds are thought to play adaptive roles in mediating osmotic adjustment and 
protecting subcellular structures in stressed plants. However, not all plants accumulate GB or proline in sufficient amounts to help averting adverse effects of abiotic stresses. Thus, different approaches have been contemplated to increase the concentrations of these compounds in plants grown under stress conditions to increase their stress tolerance. First, it is the use of traditional protocols of plant genetics and breeding to develop cultivars with natural abilities to produce high levels of these compounds under stress conditions. However, in spite of the presence of considerable genetic variation in natural production of these compounds in different plant species, little is known regarding the genetic basis (e.g. inheritance) of these traits to warrant crop improvement via traditional breeding. A second approach has been to engineer genetically plants that are capable of producing sufficient amounts of these compounds in response to environmental stresses. Although some progress has been made in introducing genes for the production of these compounds in naturally nonaccumulating or low-accumulating plant species, levels of accumulation in transgenic plants have often been low or insufficient to improve plant stress tolerance.

Further research is currently underway to improve the efficiency of this approach, in particular by taking into account factors such as the availability of substrates and metabolic fluxes in engineered plants, which may affect production of these osmolytes. A third approach, which may be considered as a short-cut method, is exogenous application of these osmolytes to plants growing under stress conditions to enhance their tolerance. Exogenous applications of GB and proline to plants, before, during, or after stress exposure, have been shown to increase the internal levels of these compounds and generally enhance plant growth and final crop yield under stress conditions. There are, however, great variations in different plant species in response to exogenous application of GB and proline. First, not all plant species are responsive to external application of these compounds. Second, the effective concentration may vary from species to species, and over-application may be toxic to some plants resulting in growth inhibition or yield reduction. Third, plants may exhibit different responses to external application of these compounds at different stages of plant development. Therefore, for effective application and commercial use of exogenous GB and proline as stimulators of crop stress tolerance, the mechanisms of actions of these compounds, the most optimal concentrations, and appropriate plant developmental stages must be carefully determined. The current research to determine specific roles of GB and proline in plant stress tolerance is expected to help improving their application as exogenous treatments to improve plant growth and productivity under stress conditions.

\section{References}

Agboma, M., Jones, M.G.K., Peltonen-Sainio, P., Rita, H. and Pehu, E. 1997a. Exogenous glycine betaine enhances grain yield of maize, sorghum and wheat grown under two supplementary watering regimes. J. Agron. Crop Sci. 178, 29-37.

Agboma, P., Peltonen-Sainio, P., Hinkkanen, R. and Pehu, E. 1997b. Effect of foliar application of glycine betaine on yield components of drought stressed tobacco plants. Exp. Agric. 33, 345-52.

Agboma, P., Sinclair, T., Jokinen, K., PeltonenSainio and P., Pehu, E. 1997c. An evaluation of the effect of exogenous glycine betaine on the growth and yield of soybean. Field Crops Res. 54, 51-64.

Alia, P.S. and Mohanty, P. 1997. Involvement of proline in protecting thylakoid membranes against free radical-induced photodamage. J. Photochem. Photobiol. $38,253-57$. 
Ashraf, M., 1994. Breeding for salinity tolerance in plants. Crit. Rev. Plant Sci.13, 17-42.

Ashraf, M., and Harris, P.J. 2004. Potential biochemical indicators of salinity tolerance in plants. Plant Sci. 166, 3-16.

Bohnert H.J., Nelson D.E. and Jensen R.G. 1995. Adaptations to environmental stresses. Plant Cell, 7, 1099-1111.

Bot, A.J., Nachtergaele, F.O. and Young, A. 2000. Land resource potential and constraints at regional and country levels. World Soil Resources Reports 90. Land and Water Development Division, FAO, Rome.

Chaves, M.M., 2009. Photosynthesis under drought and salt stress: regulation mechanisms from whole plant to cell. Ann. Bot. 103, 551-560

Chen, C., 2006. Tomato QM-like protein protects Saccharomyces cerevisiae cells against oxidative stress by regulating intracellular proline levels. Appl. Environ. Microbiol. 72, 4001-4006

Chen, C., and Dickman, M.B. 2005. Proline suppresses apoptosis in the fungal pathogen Colletotrichum trifolii. Proc. Natl. Acad. Sci. U. S. A. 102, 3459-3464

Choukr-Allah, R., 1995. The potential of halophytes in the development and rehabilitation of arid and semi-arid zones. In: Choukr-Allah, R., Malcolm, C.V., Hamdy, A. (Eds.), Halophytes and Biosaline Agriculture. Marcel Dekker, Inc., New York, pp. 1-13.

Chrominski, A., Halls, S., Weber, D.J. and Smith, B.N. 1989. Proline affects ACCtoethylene conversion under salt and water stresses in the halophyte Allenrolfea occidentalis. Environ. Exp. Bot. 29, 359-363.

Csonka, L.N., and Hanson, A.D. 1991. Prokaryotic osmoregulation: genetics and physiology. Annu. Rev. Microbiol. 45, 569-606

De Ronde, J.A., 2004. Photosynthetic response of transgenicsoybean plants, containing an Arabidopsis P5CR gene, during heat and drought stress. J Plant Physiol. 161,
1211-1224

Dudal, R., 1976. Inventory of Major Soils of the World with Special Reference to Mineral Stress. Cornell Univ. Agric. Exp. Stn Ithaca, 3 pp.

Fischer, R.A., and Byerlee, D.R. 1991. Trends of wheat production in the warmer areas: major issues and economic considerations. In: Saunders, D.A. (Ed.), Wheat for Nontraditional, Warm Areas. CIMMYT, Mexico, DF, pp. 3-27.

Flowers, T.J., and Yeo, A.R. 1995. Breeding for salinity resistance in crop plants: where next? Aust. J. Plant Physiol. 22, 875-884.

Flowers, T.J., Troke, P.F. and Yeo, A.R. 1977. The mechanism of salt tolerance in halophytes. Annu. Rev. Plant Physiol. 28, 89-121.

Gagneul, D., 2007. A reassessment of the function of the socalledcompatible solutes in the halophytic Plumbaginaceae Limonium latifolium. Plant Physiol. 144, 1598-1611

Gibson T.S., Speirs J. and Brady C.J. 1984. Salt-tolerance in plants: II. In vitro translation of mRNAs from salt-tolerant and salt-sensitive plants on wheat germ ribosomes. Responses to ions and compatible solutes. Plant, Cell and Environment 7, 579- 587.

Hanson, A.D., and Scott, N.A. 1980. Betaine synthesis from radioactive precursors in attached, water-stressed barley leaves. Plant Physiol. 66, 342-348.

Hare, P., and Cress, W. 1997. Metabolic implications of stress induced proline accumulation in plants. Plant Growth Regul. 21, 79-102

Hare, P.D., Cress, W.A. and Staden, J.V. 2002. Disruptive effects of exogenous proline on chloroplast and mitochondrial ultrastructure in Arabidopsis leaves. South African J. Bot. 68, 393-396.

Harinasut, P., Tsutsui, K., Takabe, T., Nomura, M. and Kishitani, S. 1996. Exogenous glycine betaine accumulation and increased salt tolerance in rice seedlings. Biosci. Biotechnol. Biochem. 60, 366368. 
Heyser, J.W., de-Bruin, D., Kincaid, M.L., Johnson, R.Y., Rodriguez, M.M. and Robinson, N.J. 1989. Inhibition of NaClinduced proline biosynthesis by exogenous proline in halophilic Distichlisspicata suspension cultures. $J$. Exp. Bot. 40, 225-232.

Hoque, M.A., 2008. Proline and glycinebetaine enhance antioxidant defense and methylglyoxal detoxification systems and reduce $\mathrm{NaCl}$-induced damage in cultured tobacco cells. J. Plant Physiol. 165, 813824

Kant, S., 2006. Evidence that differential gene expression between the halophyte. Thellungiella halophila and Arabidopsis thaliana is responsible for higher levels of the compatible osmolyte proline and tight control of $\mathrm{Na}+$ uptake in T. halophila. Plant Cell Environ. 29, 1220-1234

Kavi Kishor, P.B., 2005. Regulation of proline biosynthesis, degradation, uptake and transport in higher plants: its implications in plant growth and abiotic stress tolerance. Curr. Sci. 88, 424-438.

Khedr, A.H., 2003. Proline induces the expression of salt-stress responsive proteins and may improve the adaptation of Pancratium maritimum L. to saltstress. J. Exp. Bot. 54, 2553-2562

Kishor, P.B.K., Hong, Z., Miao, G.H., Hu, C.A.A. and Verma, D.P.S. 1995. Overexpression of [delta]-pyrroline-5carboxylate synthetase increases proline production and confers osmotolerance in transgenic plants. Plant Physiol. 108, 1387-1394.

Krishnamurthy, R., and Bhagwat, K.A. 1993. Effect of foliar application of prolineon the salt stressed rice seedlings. Acta Agron. Hung. 42, 267-272.

Krishnan, N., 2008. Proline modulates the intracellular redox environment and protects mammalian cells against oxidative stress. Free Radical Biol. Med. 44, 671-681

Lone, M.I., Kueh, J.S.H., Wyn Jones, R.G. and Bright, S.W.J. 1987. Influence of proline and glycine betaine on salt tolerance of cultured barley embryos. J. Exp. Bot. 38, 479-490.

Lutts, S., 2000. Exogenous glycine betaine reduces sodium accumulation in saltstressed rice plants. Int. Rice Res. Notes 25, 39-40.

Mansour, M.M.F., 2000. Nitrogen containing compounds and adaptation of plants to salinity stress. Biol. Plant. 43, 491-500.

Meek, C., Oosterhuis, D. and Gorham, J. 2003. Does foliar-applied glycine betaine affect endogenous betaine levels and yield in cotton.

Mehta, S.K., and Gaur, J.P. 1999. Heavy-metalinduced prolineaccumulation and its role in ameliorating metal toxicity in Chlorella vulgaris. New Phytol. 143, 253-259

Papageorgiou, G.C., and Murata, N. 1995. The unusually strong stabilizing effects of glycine betaine on the structure and function of the oxygen-evolving Photosystem II complex. Photosynthesis Researc. 44, 243-252.

Rajendrakumar, C.S.V., Suryanarayana, T. and Reddy, A.R. 1997. DNA helix destabilization by proline and betaine: possible role in the salinity tolerance process. FEBS Letters 410, 201-205.

Robinson, S.P., and Jones, G.P. 1986. Accumulation of glycine betaine in chloroplasts provides osmotic adjustment during salt stress. Aust. J. Plant Physiol. 13, 659-668.

Rosenzweig, C., and Parry, M.L. 1994. Potential impact of climate change on world food supply. Nature. 367, 133-138.

Santoro M.M., Liu Y., Khan S.M.A., Hou L.X. and Bolen D.W. 1992. Increased thermal stability of proteins in the presence of naturally occurring osmolytes. Biochemistry 31, 5278-5283.

Satoh, R., Nakashima, K., Seki, M., Shinozaki, K. and Yamaguchi-Shinozaki, K. 2002. ACTCAT, a novel cis-acting element for proline- and hypoosmolarity-responsive expression of the ProDH gene encoding proline dehydrogenase in Arabidopsis. Plant Physiol. 130, 709- 719. 
Schat, H., 1997. Heavy metal-induced accumulation of free proline in a metaltolerant and a nontolerant ecotype of Silene vulgaris. Physiol. Plant. 101, 47782

Sharma, P., and Dubey, R.S. 2005. Modulation of nitrate reductase activity in rice seedlings under aluminium toxicity and water stress: role of osmolytes as enzyme protectant. J Plant Physiol. 162, 854- 64

Sharp, R.E., Boyer, J.S., Nguyen, H.T. and Hsiao, T.C. 1996. Genetically engineered plants resistant to soil drying and salt stress: how to interpret osmotic relations. Plant Physiol. 110, 1051-1053.

Sharp, R.E., Wu, Y., Voetberg, G.S., Saab, I.N. and LeNoble, M.E. 1994. Confirmation that abscisic acid accumulation is required for maize primary root elongation at low water potentials. J. Exp. Bot. 45, 1717-1743.

Smirnoff, N., and Cumbes, Q.J. 1989. Hydroxyl radical scavenging activity of compatible solutes. Phytochemistry 28, 1057-1060

Szekely, G., 2008. Duplicated P5CS genes of Arabidopsis play distinct roles in stress regulation and developmental control of prolinebiosynthesis. Plant J. 53, 11-28

Varshney, K.A., Gangwar, L.P. and Goel, N. 1988. Choline and betaine accumulation in Trifolium alexandrinum L. during salt stress. Egypt J. Bot. 31, 81-86.

Venkatesan, A., Chellappan, K.P. 1998. Accumulation of proline and glycine betaine in Ipomoea pescaprae induced by $\mathrm{NaCl}$. Biol. Plant. 41, 271- 276.

Voetberg, G.S., and Sharp, R.E. 1991. Growth of the maize primary root tip at low water potentials. III. Role of increased proline deposition in osmotic adjustment. Plant Physiol. 96, 1125-1130.

Wang, F., 2009. Relationship between proline and $\mathrm{Hg} 21$-induced oxidative stress in a tolerant rice mutant. Arch. Environ. Contam. Toxicol. 56, 723-731

WeiBing, X., and Rajashekar, C.B. 1999. Alleviation of water stress in beans by exogenous glycine betaine. Plant Sci. 148, 185-192.

Weimberg, R., Lerner, H.R. and PoljakoffMayber, A. 1984. Changes in growth and water soluble solute concentrations in Sorghum bicolor stressed with sodium and potassium. Physiol. Plant. 62, 472480.

Weretilnyk, E.A., Bednarek, S., McCue, K.F., Rhodes, D. and Hanson, A.D. 1989. Comparative biochemical and immunological studies of the glycine betaine synthesis pathway in diverse families of dicotyledons. Planta 178, 342-352.

Yan, H., Gang, L.Z., Zhao, C.Y. and Guo, W.Y. 2000. Effects of exogenous prolineon the physiology of soyabean plantlets regenerated from embryos in vitro and on the ultrastructure of their mitochondria under $\mathrm{NaCl}$ stress. Soybean Sci. 19, 314319.

Yancey P.H., Clark M.E., Hand S.C., Bowlus R.D. and Somero, G.N. 1982. Living with water stress: evolution of osmolyte systems. Science 217, 1214-1222.

\section{How to cite this article:}

Kanu Murmu, Sidhu Murmu, Champak Kumar Kundu and Purnendu Sekhar Bera. 2017. Exogenous Proline and Glycine Betaine in Plants under Stress Tolerance. Int.J.Curr.Microbiol.App.Sci. 6(9): 901-913. doi: https://doi.org/10.20546/ijcmas.2017.609.109 